\title{
Vivência profissional: subsídios à atuação em HIV/Aids ${ }^{1}$
}

\author{
Joana Filipa Afonso Monteiro \\ Marco Antonio de Castro Figueiredo ${ }^{2}$ \\ Universidade de São Paulo, Ribeirão Preto-SP, Brasil
}

\begin{abstract}
Resumo: No contexto do HIV/Aids, alguns desdobramentos psicossociais são elementos-chaves para a concepção de projetos voltados à superação de dificuldades determinadas pela racionalidade das abordagens especializadas. Este trabalho visou identificar, no processo de atendimento a pessoas com Aids, alguns elementos emergentes da relação terapêutica, com o objetivo de subsidiar a concepção de programas de formação profissional. Entrevistas semiestruturadas com dez profissionais junto a um hospital-escola do interior de São Paulo permitiram estabelecer seis categorias temáticas relacionadas ao contexto do atendimento em HIV/Aids: tratamento dispensado, relação estabelecida, limites da atuação, abordagens teleológicas, apropriação do trabalho e contraponto às vivências da atuação. Tais resultados demonstram que o atendimento a pessoas com HIV/Aids exige outros elementos, além do conhecimento técnico especializado, determinando uma simetria no estabelecimento do vínculo profissional-paciente e viabilizando uma construção conjunta com o trabalho das equipes.
\end{abstract}

Palavras-chave: Síndrome da imunodeficiência adquirida, formação profissional, subjetividade.

\section{Professional experience: support the work in HIV/Aids}

\begin{abstract}
Some psychosocial developments in the context of HIV/Aids are key elements for designing projects focused on overcoming difficulties generated by the rationality of specialized approaches. This study aimed to identify some emerging elements of the therapeutic relation in the process of caring for people with Aids in order to support the development of professional training programs. Semi-structured interviews with ten professionals in a teaching hospital in the interior of São Paulo permitted the establishment of six thematic categories related to the context of HIV/Aids care: delivered treatment, established relationship, limits of care, teleological approaches, work ownership and counterpoint to experience of practice. These results reveal that caring for people with HIV/Aids requires other elements in addition to specialized technical knowledge, which in turn generates symmetry in the establishment of bonds between professional-patient, allowing to construct together with the professional teams work.
\end{abstract}

Keywords: Acquired immune deficiency syndrome, professional education, subjectivity.

\section{Vivencia profesional: subsidios a la actuación en VIH/Sida}

Resumen: En el contexto del VIH/Sida, algunos desdoblamientos psicosociales son elementos clave para el diseño de proyectos destinados a superar dificultades determinadas por la racionalidad de los enfoques especializados. Esto estudio tuvo como objetivo identificar, en el proceso de atención a las personas con el Sida, algunos elementos emergentes en la relación terapéutica, con el objetivo de subsidiar el desarrollo de programas de formación profesional. Entrevistas semi-estructuradas con diez profesionales de salud en el hospital escuela del interior de la provincia de São Paulo, permitirán establecer seis categorías temáticas en relación con el contexto de la atención al VIH/Sida: tratamiento dispensado, relación establecida, límites de la actuación, enfoques teleológicos, apropiación del trabajo y contrapunto a las vivencias de la actuación. Estos datos muestran que la atención a las personas con el VIH/Sida demanda otros elementos, además de los conocimientos técnicos especializados, determinando una simetría en la construcción del vínculo profesional-paciente, posibilitando una construcción conjunta de la labor dentro de los equipos.

Palabras clave: Sindrome de inmunodeficiencia adquirida, educación profesional, subjetividad.

$\mathrm{O}$ advento da Aids aconteceu em um momento em que, ao menos para os países desenvolvidos, a maioria das epidemias era considerada extinta ou controlada. Colocou a medicina frente aos seus limites, diante de uma doença incurável, fora do controle de vetores e relacionada, entre outras coisas,

1 Apoio: CAPES. Artigo derivado da Dissertação de Mestrado O processo de trabalho em HIV/Aids: A visão dos profissionais, defendida pela primeira autora e orientada pelo segundo autor, junto ao Programa de Pós-graduação em Psicologia da Faculdade de Filosofia, Ciências e Letras de Ribeirão Preto da Universidade de São Paulo. Este texto foi revisado seguindo Acordo Ortográfico da Língua Portuguesa (1990), em vigor a partir de $1^{\circ}$ de janeiro de 2009 .

2 Endereço para correspondência:

Prof. Dr. Marco Antonio de Castro Figueiredo. Universidade de São Paulo. Faculdade de Filosofia, Ciências e Letras de Ribeirão Preto. Departamento de Psicologia e Educação. Avenida dos Bandeirantes, 3900. Monte Alegre. CEP 14040-901. Ribeirão Preto-SP, Brasil. E-mail: marcoacf@usp.br ao comportamento de indivíduos e à determinação da sociedade civil (Camargo Junior, 1994; Terto Junior, 1996).

Em meio ao sofrimento provocado pelo seu surgimento, a Aids trouxe a discussão sobre os paradoxos sustentados em nossa sociedade, junto à formação e atuação em saúde.

Considerando que o contágio por HIV estava inicialmente pautado na noção de grupos de risco, os profissionais de saúde enfrentavam dois desafios: uma doença desconhecida e trabalhar com segmentos socialmente marginalizados. Bastos (conforme citado por Oltamari, 2004, p. 175), tece algumas considerações sobre a Aids enquanto fenômeno científico, relacionando-a aos movimentos sociais:

$\mathrm{O}$ advento da Aids foi um grande retrocesso na supremacia do saber médico especializado. Essa doença desafiou a ciência e foi um empecilho aos avanços da medicina (...) que teve que se deparar com uma 
síndrome tão perniciosa que, ademais, possuía um agravante: era contagiosa. Além disso, a Aids revelou a falência do projeto de modernidade, que tem na ciência sua condição essencial, ao trazer à tona os problemas relativos ao embate dos "egos" e às lutas por poder no meio científico, além de explicitar o preconceito que há em nossa sociedade.

O avanço da epidemia estendeu à sociedade civil a polêmica da atuação em HIV/Aids revendo as concepções pautadas nos elementos técnicos especializados, em detrimento dos elementos psicossociais da atenção, uma vez que não contemplava suas especificidades e seus desdobramentos para o convívio social da pessoa com HIV/Aids (Alves \& Ramos, 2002; Ribeiro, Coutinho, \& Saldanha, 2004; Sadala \& Marques, 2006).

Nos hospitais, muitos trabalhos têm sido realizados, visando compreender os limites do atendimento a pessoas com HIV/Aids, considerando as perspectivas de profissionais e usuários (Barroso \& Galvão, 2007; Herrera, Campero, Caballero, \& Kendall, 2008; Oliveira \& França Junior, 2003). Não obstante, poucos estudos partem da vivência do profissional, ou seja, das percepções dos profissionais sobre si e seu cotidiano de trabalho. Assim, este estudo tem como objetivo identificar, nos aspectos contextuais do trabalho e a partir das vivências de profissionais que atendem pessoas com HIV/Aids, alguns elementos subsidiários à concepção de alternativas para uma atuação de qualidade.

\section{Método}

O estudo foi realizado junto à Unidade Especial de Tratamento de Doenças Infecciosas do Hospital das Clínicas da Faculdade de Medicina de Ribeirão Preto da Universidade de São Paulo (FMRP-USP). Esta Unidade, em funcionamento há 10 anos, é centro de referência para o atendimento à população da cidade e grande região. A Unidade é composta por Ambulatório, Hospital-dia e Enfermaria.

Participaram do estudo dez profissionais: três médicos infectologistas, dois enfermeiros, um auxiliar de enfermagem, um assistente social, um psicólogo e dois funcionários administrativos que lidam diretamente com pacientes. $\mathrm{O}$ número de participantes foi determinado pelo critério de saturação de conteúdos (Minayo, 2004). Considerando a importância da experiência para a participação no estudo, esta foi condicionada a, no mínimo, dois anos de trabalho na Unidade. As entrevistas foram realizadas no local de trabalho, em horários preestabelecidos e salas indicadas pelos participantes. O elenco de pessoas entrevistadas foi composto por seis mulheres e quatro homens, com idades entre 29 e 53 anos.

Em conformidade com os preceitos éticos, os participantes firmaram, com a equipe de pesquisadores, um Termo de Consentimento Livre e Informado, aprovado pela Comissão de Normas Éticas da Instituição onde foi feita a pesquisa.

\section{Procedimento}

Foram realizadas entrevistas individuais, audiogravadas e semiestruturadas, segundo o procedimento de Evocação-Enunciação-Verificação proposto por Figueiredo (1998) e descrito a seguir: (a) Evocação: após o rapport, foi solicitado ao participante que refletisse, durante um tempo determinado (aproximadamente dois minutos) sobre o que considerava mais relevante a respeito do objeto de estudo; (b) Enunciação: após ter pensado sobre o que lhe foi solicitado, foram entregues à pessoa uma folha de papel e uma caneta, pedindo-lhe que escrevesse, com as próprias palavras, o que de mais importante havia pensado; (c) Averiguação: uma vez recolhidos os enunciados, a entrevista era iniciada e, com o consentimento do profissional, era acionado o gravador. Nesta etapa, eram realizadas a verificação e a discussão dos conteúdos evocados, visando ao esclarecimento de aspectos menos específicos dos conteúdos.

Após a transcrição integral dos depoimentos, estes foram sistematizados com base no destaque e identificação de categorias temáticas a posteriori, a partir de sínteses sucessivas, realizadas em duas fases: (a) Primeira Junção: realizada a partir das transcrições das entrevistas, a síntese se efetuou partindo de conteúdos comuns dentro de uma mesma entrevista; (b) Segunda Junção: realizada sobre os conteúdos identificados na primeira junção, uma segunda síntese foi realizada sobre conteúdos comuns às diversas entrevistas. Esta sistematização é descrita a seguir:

(1) A Primeira Fase foi realizada sobre as transcrições das entrevistas. Nesta fase, a junção foi efetuada partindo de conteúdos comuns dentro de uma mesma entrevista. Compreende as seguintes etapas: (a) leitura inicial: foi realizada uma série de leituras em profundidade, para identificar trechos preliminares, ligados às Categorias Temáticas de conteúdos tratados nas entrevistas; (b) marcação: nesta etapa, alguns trechos das transcrições foram selecionados, destacando os conteúdos correspondentes às Categorias Temáticas, além de outros conteúdos julgados significantes; (c) corte: os trechos selecionados foram, então, retirados do texto; (d) primeira junção: Os trechos recortados foram agrupados, por pessoa, e dispostos em um protocolo de análise; (e) notação: observações marginais foram feitas sobre cada um dos trechos, comentando-os e localizando-os na literatura e no contexto das entrevistas; (f) organização: as observações marginais serviram como referencial para proceder a organização dos dados em uma segunda junção, onde foram agrupados os trechos de todos os entrevistados dentro de uma mesma Categoria Temática.

(2) A Segunda Fase foi realizada sobre a Segunda Junção, se referindo aos conteúdos comuns às várias sessões de entrevistas. Compreendeu etapas similares à primeira parte: (g) leitura inicial: compreendeu uma série de leituras em profundidade, onde foram identificados alguns trechos preliminares, agora por Categoria Temática; (h) organização: os trechos selecionados foram agrupados e classificados segundo as subcategorias ou seja, em função de conteúdos 
específicos de uma das Categorias Temáticas, em particular; (i) notação: tomando um protocolo semelhante ao da Notação realizada na primeira fase, as primeiras notações foram ampliadas e relacionadas, entre si, dentro de uma mesma Categoria Temática; (j) redação final: finalmente, com base na segunda notação, foi elaborada a redação dos trabalhos.

A Tabela 1, a seguir, apresenta as fases desse procedimento:

Tabela 1

Etapas do procedimento de análise de conteúdos sobre o material transcrito nas entrevistas

\begin{tabular}{cl}
\hline & A. Leitura Inicial \\
& B. Marcação \\
Primeira Fase(*) & C. Corte \\
(Participantes) & D.Primeira Junção \\
& E. Notação \\
& F. Organização \\
\hline Segunda Junção (Primeira Síntese) \\
\hline
\end{tabular}

*Conteúdos relacionados a várias Categorias, no mesmo sujeito.

**Conteúdos de vários sujeitos em uma mesma Categoria

\section{Referencial Teórico}

O estudo foi conduzido sob a perspectiva da hermenêutica-dialética, proposta por Minayo (2003, 2004) e que, via discurso, permite a interpretação dos fenômenos sociais. Segundo a autora, a unidade temporal da hermenêutica é o presente

no qual se marca o encontro entre o passado e o futuro, ou entre o diferente e a diversidade dentro da vida atual, mediada pela linguagem. No entanto (...) nem sempre a linguagem é considerada transparente em si mesma, pois tanto é possível chegar a um entendimento (nunca completo e nunca total), como a um não entendimento (...) a compreensão se refere, ao mesmo tempo, ao que é comum, por comparação, e ao que é específico, como contribuição peculiar de cada autor. (Minayo, 2003, p. 84)

Sob a perspectiva da pesquisa qualitativa, foi adotado o referencial do materialismo histórico, considerando a subordinação das ciências à lógica do modo de produção vigente e sua determinação no processo de reificação instalado no trabalho em saúde. E, nesse contexto, alguns teóricos da Saúde Coletiva que abordam o processo de trabalho em saúde (Campos, 2000) e a formação médica na atuação em HIV/ Aids (Camargo Junior, 1994, 2005) foram utilizados como aporte teórico na discussão dos resultados.

\section{Resultados e Discussão}

A análise de conteúdos dos depoimentos permitiu a identificação de seis Categorias Temáticas: (a) tratamento dispensado; (b) relação estabelecida; (c) limites da atuação; (d) abordagens teleológicas; (e) contraponto às vivencias da atuação; (f) apropriação do trabalho. Tais Categorias Temáticas foram desdobradas em Subcategorias, com seus respectivos conteúdos, como pode ser observado na Tabela 2 a seguir:

Tabela 2

Categorias temáticas e respectivas subcategorias de conteúdos identificados pela análise das transcrições das entrevistas

\begin{tabular}{ll}
\hline \multicolumn{1}{c}{ Categorias temáticas } & Subcategorias (conteúdos) \\
\hline \multirow{3}{*}{ 1. Tratamento dispensado } & abordagens \\
& 1.2. Especialização \\
& 1.3. Orientação \\
& 2.1. Vínculo \\
2.2. Relações informais & 2.3. Incentivo material \\
2. Relação estabelecida & 3.1. Iminência da morte \\
& 3.2. Prognóstico \\
3.3. Impotência \\
3.4. Desgaste emocional \\
4.1. Remissão \\
4.2. Equilíbrio \\
5.1. Histórias de vida \\
5.2. Sofrimento \\
5.3. O dia da cura \\
5.4. Controle emocional \\
5.5. Racionalidade clínica \\
6.1. Auto-realização \\
profissional \\
6.2. Aprendizagem \\
informal \\
\hline
\end{tabular}

A Categoria Temática 1, Tratamento dispensado aos pacientes, se liga à percepção dos profissionais sobre as necessidades das pessoas atendidas, à estruturação do trabalho em saúde e à visão sobre as formas de suprir tais demandas. Foi desdobrada em três Subcategorias: Complementaridade de Abordagens, Especialização e Orientação.

A estruturação da formação em saúde e, consequentemente, dos serviços nesta área é determinada pela racionalidade das ciências (Camargo Junior, 1992, 2005), ligando-se às formas protocolares de controle do trabalho, em todos os 
seus níveis. Desta forma, embora a atuação em saúde demande atenção integral ao paciente, voltada para todos os aspectos que englobam o cuidado, a dicotomia entre habilidade técnica e competência psicossocial prevalece e, esta última, na maioria das vezes, é relegada a um segundo plano, como mostra o depoimento a seguir:

Acho interessante esse contato com a equipe multidisciplinar... Você trata o paciente, a parte física... Ele tem todo um aspecto psicológico, social que, às vezes, a gente não fica sabendo... Todos meus pacientes passaram com a assistente social, a psicóloga... Eu discuto... acho bacana saber o que está acontecendo... (Profissional 7)

Todavia, essa dicotomia apresentou configurações diferentes. Sem negar os aspectos psicossociais da atuação, há um sentimento de inaptidão e impotência para suprir as demandas trazidas, em virtude dos limites impostos pela especialização e considerando a complexidade das abordagens ao HIV/Aids (Figueiredo, 2000). O depoimento, a seguir, ilustra esta questão:

As vezes, tenho medo de perguntar muito porque, como não tenho formação como vocês (refere-se aos psicólogos)... Tenho medo de estar entrando numa área que não é minha e não saber como resolver. Teve uma época que eu perguntava muito, queria ajudar muito o paciente nessa parte emocional só que eu não tenho formação pra isso... Eu sentia que, às vezes, eu ficava como que amiga do paciente, mas tem coisa que não é como amiga que tem que fazer. As vezes precisa de um apoio diferente, uma abordagem que o psiquiatra e o psicólogo podem dar mais adequadamente... (Profissional 7)

A esse respeito, Ayres (2004, p. 84) faz a seguinte consideração:

O modo como aplicamos e construímos tecnologias e conhecimentos científicos determina limites para o que podemos enxergar como necessidades de intervenção em saúde. Precisamos ter claro também que nem tudo que é importante para o bem estar pode ser imediatamente traduzido e operado como conhecimento técnico (...) precisamos estar atentos para o fato de que nunca, quando assistimos à saúde de outras pessoas, mesmo estando na condição de profissionais, nossa presença na frente do outro se resume ao papel de simples aplicador de conhecimentos.

Assim, observa-se que a Complementaridade de Abordagens constitui uma alternativa utilizada por esses profissionais no tratamento a seus pacientes: "Ofereço algum tipo de ajuda. A gente tem algumas possibilidades, com a psicologia, a psiquiatria...” (Profissional 9).
Silva e cols. (2002) afirmam que as demandas trazidas pela Aids não encontram respostas no modelo biomédico de atuação em saúde. Para os profissionais que atuam em HIV/ Aids, o trabalho multidisciplinar exige uma superação, enquanto justaposição de ações. Embora haja a percepção da necessidade de se atender às demandas psicossociais trazidas pelos pacientes, a especialização se apresenta como uma barreira para o suprimento dessas necessidades.

Dessa forma, observa-se que a Complementaridade de Abordagens durante a atuação, representa uma justaposição de ações. Segundo Silva e cols. (2002), esta perspectiva parcelar precisa ser superada e uma das alternativas para esta superação seria a discussão desta questão, pela equipe, visando à construção conjunta do trabalho.

A Orientação ao paciente se configurou como um desdobramento do Tratamento, se referindo à necessidade de o profissional realizar um trabalho junto aos pacientes, procurando torná-los agentes multiplicadores de prevenção ao HIV: "Fico com vontade que todos evitem, converso com os pacientes falo pra eles: tem que usar preservativo... conversa com a tua filha..." (Profissional 3).

Há que salientar, entretanto, que neste estudo poucos participantes falaram a respeito de orientação ao paciente, considerando o trabalho de prevenção. Aqui, duas questões podem ser levantadas: a prevenção durante o atendimento já estaria incorporada às atividades de rotina e refletir sobre esta, não seria necessário, ou a prevenção não faria parte das atividades prescritas para o atendimento. No entanto, independente do motivo, este fato precisa ser contemplado por outros estudos. Esse tema, extremamente complexo, demanda sua inclusão na rotina do atendimento já que "é necessário que haja uma indissociabilidade da prevenção e da assistência nos serviços de saúde" (Camargo Junior, 2003, p. 74). Além do Sistema Único de Saúde ter como um de seus princípios o conceito de integralidade, a prevenção também se justifica para que não ocorra, por parte da pessoa, uma contaminação por um vírus de cepa resistente e que esta não contamine outras pessoas.

A Categoria 2, Relação Estabelecida com a pessoa atendida, se refere ao vínculo profissional-paciente-familiar, e à necessidade de o profissional oferecer suporte ao paciente, visando ao suprimento de suas necessidades psicológicas e à resolução de conflitos no âmbito do tratamento. Deste modo, esta Categoria se desdobrou em quatro Subcategorias Temáticas: Vínculo, Relações Informais, Incentivo Material e Acolhimento.

Segundo alguns profissionais entrevistados, a própria natureza do trabalho propicia a formação de Vínculo entre profissional e paciente: "É fácil você ficar muito amiga dos pacientes... então tem uns pacientes... que eu gosto demais... (Profissional 7)". E, na maioria das vezes, o vínculo torna-se fundamental para a realização de um bom trabalho:

Gosto de conversar, de me relacionar com as pessoas... especialmente com os meus pacientes. Tento deixar eles à vontade pra poder falar... Trazer as 
questões, conheço quase que a vida de todo mundo... vida pessoal... problemas... família... Conheço porque faz muito tempo que eu os conheço e eu tento dar o espaço pra gente poder falar disso... (Profissional 9)

Embora alguns profissionais tenham considerado o Vínculo estabelecido necessário à realização de um bom trabalho, outros demonstraram algumas dificuldades para compreender a importância do vínculo para o tratamento, fundamentados na crença de que o profissional tem de ser neutro e não deve se vincular ao paciente: "Por mais profissional que você seja não tem como você não criar vínculo com pacientes..." (Profissional 8).

Tal concepção, enquanto um desdobramento da dicotomia entre competência técnica e sensibilidade social, é um lugar comum na formação em saúde (Camargo Junior, 2005) e sua superação é primordial para o estabelecimento de um vínculo construtivo com a pessoa atendida.

Segundo Rissi (2001), a adesão ao tratamento por parte dos pacientes é extremamente complexa e, basicamente, está ligada a um vínculo de confiança e cumplicidade, estabelecido entre o profissional e a pessoa atendida.

A adesão ao tratamento por antirretrovirais tem despertado uma grande preocupação que pode ser observada pelo número crescente de trabalhos a respeito. Muitos destes estudos têm enfatizado a importância da construção de um vínculo terapêutico para a manutenção do tratamento (Cardoso \& Arruda, 2004; Oliveira \& França Junior, 2003; Resuto, Mendes, Oliveira, \& Lourenço, 2000). Dessa forma, a participação ativa do paciente no processo de atendimento representa um grande desafio para os profissionais que atuam em HIV/Aids e que, frente a esta questão, necessitam repensar sua prática.

As relações estabelecidas durante o atendimento poderiam favorecer a compreensão da importância deste vínculo e seus desdobramentos para o tratamento, ajudando o profissional no manejo das dificuldades para se associar à pessoa atendida e favorecendo uma construção compartilhada de formas de enfrentamento, na luta contra o HIV/Aids.

O suporte afetivo e social se configurou no estudo como um elemento efetivo da atuação profissional, apresentando vários desdobramentos na práxis via estabelecimento de relações entre profissionais e pacientes: Relações Informais, Incentivo Material e Acolhimento: "Como são poucos, há uma proximidade... a gente brinca, alguns já sabem qual é o meu time de futebol ... a gente conhece a família... esposas... filhos... é um contato bem próximo..." (Profissional 6); "Eles vêm, a gente acolhe... essa é a minha forma de estar dando uma atenção para o paciente, fazendo esses encaixes que eu posso fazer... se tem algum antibiótico que não tem e eles precisam, eu tento conseguir; do nosso grupo, todos conseguiram cesta básica, pra estar dando lanche... é a minha forma de contribuir..." (Profissional 7); "Em vez de ficar bravo, acolher, dar ajuda, esse é o papel que a gente tem" (Profissional 9).
O acolhimento é uma das demandas intrínsecas ao atendimento à pessoa com HIV/Aids e tem de estar presente nas unidades assistenciais e nas suas equipes. Vai muito além da adesão e da ausculta e não se prende a nenhuma intervenção de natureza biomédica, uma vez que se liga às vivências decorrentes das vicissitudes de ser portador do HIV ou doente de Aids (Silva e cols., 2002).

O suporte afetivo e social que os profissionais estudados acreditam dar aos pacientes coincide com algumas reflexões de Oliveira e França Junior (2003) a respeito do trabalho dentro de uma equipe multiprofissional de um ambulatório especializado em HIV/Aids. Segundo os autores, nestas discussões emergiu, entre outros temas, a motivação da equipe que a leva, diante das dificuldades sociais e subjetivas dos usuários, a adotar iniciativas individuais para resolução. Tal motivação estaria relacionada com sentimentos de compaixão dos profissionais para com os usuários:

A compaixão pode ser compatibilizada com simetria, em síntese, quando aquele com quem partilhamos o caminho for tomado como autêntico interlocutor e não apenas como um "objeto" de nossas iniciativas. A partir do reexame crítico da compaixão, pensamos que a avaliação da equipe sobre a atenção à saúde pode lograr um importante salto de qualidade, na medida em que consiga colocar em relação o impulso compassivo... com o princípio de equidade (não igualdade, ressalte-se) entre profissionais e usuários - também um valor resguardado pela equipe. (Oliveira \& França Junior, 2003, p. 695)

É primordial que as equipes repensem a relação estabelecida com os usuários, pois o suporte social e afetivo dentro de uma relação assimétrica não contempla, adequadamente, a função da equipe de saúde que é, entre outras coisas, promover a autonomia dos usuários, tornando-os sujeitos ativos em seu tratamento.

A autonomia é o modo de ser do ser humano e, portanto, uma precondição para a saúde e para a cidadania. Sem essa perspectiva, uma política de saúde não pode ser considerada como tal. Assim, a busca da construção da autonomia do paciente no processo saúde/doença passa a ser fundamental. Ela deve ser construída em um processo de produção contínua, em sua inter-relação com a dependência, no cotidiano, mesmo quando limitada como na doença. (Soares \& Camargo Junior, 2007, p. 43)

A terceira Categoria Temática, Limites da Atuação, relacionada ao caráter específico das diversas abordagens ao atendimento em Aids, foi desdobrada em quatro Subcategorias: Iminência da Morte, Prognóstico, Impotência e Desgaste Emocional.

Foi observado que trabalhar com HIV/Aids é trabalhar sob a Iminência da Morte que favorece sentimentos de 
antecipação sobre o desfecho final, reforçados pelo caráter pessimista do Prognóstico que, por sua vez, define os limites da ação e da prática profissional, gerando sentimentos de impotência e ansiedade nos profissionais, considerando a evolução clínica do paciente: "Ao mesmo tempo que você vê aquele paciente bem, que consegue se reerguer, você fica com aquela coisa ... até quando ele vai conseguir se manter?" (Profissional 8).

Tenho dificuldade de aceitar que uma pessoa se tornou como um objeto... não fala... não se movimenta, mas que ao mesmo tempo tem uma pulsão. É como um objeto, mas que tem um rosto humano. Fico pensando... ele teve uma história, viveu, teve alegrias, tristezas, e agora está numa situação de objeto. E pensar que quem vai pra casa tem a possibilidade de voltar pra morrer aqui, ou de morrer em casa... (Profissional 6)

O estado clínico dos pacientes incide diretamente sobre a autoestima dos profissionais, uma vez que estes incorporam a responsabilidade de mantê-los no caminho do tratamento, se responsabilizando também pela qualidade de vida via informação e suporte oferecidos às pessoas atendidas (Rissi, 2001).

Um terceiro elemento, que se apresenta como limite ao atendimento, é a Impotência suscitada na atuação e sentida em situações comuns no cotidiano do trabalho com HIV/ Aids. Neste estudo, o sentimento de impotência esteve comumente ligado ao caráter irreversível do prognóstico e à finitude humana, além da descontinuidade do trabalho realizado, em virtude das vicissitudes familiares, sociais e políticas da Aids. Os depoimentos, a seguir, ilustram tais sentimentos, vivenciados pelos profissionais:

É bom saber que você fez tudo que podia... Todo mundo fez tudo o que podia fazer... Aquela hora que você vê que a pessoa está no estado vegetativo é ruim... Você está falando, mas não vai estar sendo ouvido. É a pior hora, quando você não pode falar nada e nem fazer nada... Nem com a pessoa, nem com os familiares... Você aprendeu um monte de coisas durante a vida inteira e que não pode usar nada, naquele momento... Você vê a fragilidade do ser humano, nós todos somos frágeis... A gente não quer admitir... Você vê que a qualquer minuto você pode morrer... A gente acaba parando um pouco para pensar nisso... (Profissional 1)

Quando tenho que acionar o conselho, quando sei que a criança foi abrigada, pra mim é a morte. Me sinto fracassada... Foram anos batalhando em cima daquele caso, tentando fazer com que aquela criança pudesse permanecer na sua família... Na hora que você vê que a família não deu conta... Logicamente, ela não teve o amparo necessário, lá fora... isso frustra ... O adulto também é assim... paciente que é usuário de droga não tem suporte familiar, tem vontade de se recuperar, quer se tratar, mas está muito além das forças dele e aí você vai encaminhar pra onde? Não tem pra onde... O problema está ali na tua frente e você não tem o que fazer, você sabe que nada vai funcionar... (Profissional 8)

Segundo R. M. Figueiredo (1994), há sempre uma grande mobilização interna por parte dos profissionais quando um paciente vem a óbito, ou quando são levados a procedimentos para manter a vida em condições artificiais.

Muitos desses profissionais, quando vivenciam a morte do paciente, se defrontam com sua própria finitude e, nesses momentos de óbito, os sentimentos de impotência e menosvalia são difíceis de serem negados.

Dessa forma, observa-se que por mais que a formação em saúde paute a atuação no caráter técnico retirando a subjetividade do profissional, como pode ser observado nos cursos de graduação onde a temática da morte ou não é considerada ou é de forma superficial, a atuação suscita, muitas vezes, nos profissionais questões de ordem subjetiva.

Nesse sentido, a discussão sobre a morte e o morrer tanto na formação como na atuação dos profissionais de saúde torna-se fundamental a medida que pode propiciar a elaboração dos medos e fantasias que a questão da morte encerra (Quintana, Kegler, Santos, \& Lima, 2006).

Quanto à descontinuidade do tratamento, em decorrência da estruturação dos serviços de saúde, a percepção dos profissionais estudados é confirmada pela literatura. A atenção às pessoas com HIV/Aids é limitada, em virtude da qualidade dos serviços de saúde, na esfera pública, envolvendo a inexistência de programas psicossociais em certas regiões, demora no agendamento, inadequação da estrutura de alguns serviços e ausência de programas voltados ao incentivo de participação no tratamento (Camargo Junior, 2003; Sadala \& Marques, 2006).

Finalmente, o Desgaste Emocional decorrente da atuação em HIV/Aids é visto como um elemento limitante à atuação. Este desgaste é decorrente da grande mobilização interna dos profissionais, frente às diversas situações vivenciadas na prática, e ocorre mediante vivências distintas. O contato com o sofrimento do outro e as dificuldades pessoais do profissional quanto ao manejo de tal situação, constitui uma ocasião propícia para o desgaste afetivo, potencializado pela presença de complicações clínicas, sobretudo no caso de óbito. Da mesma forma, respostas afetivas e revolta das pessoas frente à doença podem se transferir para o próprio profissional:

Fiquei muito chateada. Foi uma criança que atendi, que estava muito grave. Eu estava atendendo... Ela, a mãe, conversando com a criança, pedindo perdão, 


\begin{abstract}
falando que amava... Aquilo mexeu comigo... Me incomodou, ver aquele sofrimento da mãe... na hora que cheguei em casa, entrei no chuveiro, ai me veio tudo aquilo: A cena... Eu ficava até ouvindo que ela tava falando, a situação, a história deles... Eu fiquei mal aquele dia... (Profissional 4)
\end{abstract}

Às vezes o paciente que você vê bem hoje, amanhã está ruim... Você fica chateado, porque o cara vem todo dia aí... ontem, semana passada no último retorno, hoje está de maca, vem de cadeira de roda, isso chateia a gente... (Profissional 5)

Têm pacientes que têm dificuldade de entender a situação na qual eles estão e eles se revoltam; tem paciente que transfere pra gente tudo o que está sentindo de tristeza e revolta, em relação ao tratamento... Não importa o que eu sinta... Tenho que manter a cabeça fria... Isso é muito estressante... (Profissional 6)

Tais sentimentos são com frequência citados na literatura considerando a saúde mental dos profissionais da saúde e demonstrando que os limites do manejo do desgaste emocional, inerente ao trabalho, são, potencialmente, causadores de doenças mentais (Nogueira-Martins, 2003).

Sadala e Marques (2006), em estudo com profissionais de unidades especializadas para o atendimento a pessoas com HIV/Aids, verificaram que o trabalho produz sentimentos de angústia, impotência e ansiedade na equipe, decorrentes do contato constante com a morte, violência sexual e drogadição, situações para as quais os profissionais não se consideram habilitados.

No presente trabalho, a violência sexual não foi mencionada pelos profissionais. A ausência de tal conteúdo nos depoimentos pode ser indício de dificuldades para incorporar alguns elementos fora do setting imediato do atendimento, envolvendo processos subjacentes ao cuidado, como papéis de gênero, vulnerabilidade social e pauperização. Reconhecer tais elementos seria identificar questões que vão além do caráter específico do tratamento, o que poderia remeter o atendimento para um outro plano, além das questões imediatas do trabalho nos hospitais e serviços de saúde.

Para M. A. C. Figueiredo (1994), o reconhecimento de tais elementos poderia minimizar o estigma e as dificuldades emocionais, subjacentes à atuação profissional em HIV/ Aids. No entanto, tais ações "não podem se realizar sem um investimento no suporte psicológico ao profissional, acompanhando e orientando seu trajeto na direção de uma interação equilibrada com a pessoa que está sendo atendida" (p. 56).

A quarta Categoria, Abordagens Teleológicas, compreende um conjunto de crenças, desenvolvidas pelos profissionais, para o manejo de possíveis incongruências e dissonâncias do trabalho, contendo duas Subcategorias de conteúdos, ligados à Remissão e ao Equilibrio: "Dando um incentivo à pessoa, você sente o bem que você faz a ela e Deus te ajuda também, e eu me sinto bem" (Profissional 1).

Eu gosto daqui... Eu entro me harmonizando com o hospital... Eu e esse local somos um só. E em matéria de espiritualidade eu leio Isaías 341. É muito legal pra mim, para me proteger... quando eu não faço isso eu tenho uns atritos muito pesados aqui dentro (Profissional 1)

As Abordagens Teleológicas são categorias que dão visibilidade a algumas formas de enfrentamento em relação ao sofrimento decorrente do trabalho. Tais abordagens relegam o enfrentamento a um plano superior, eximindo, assim, o profissional de responsabilização sobre o sofrimento do outro, tornando-o absoluto. Não obstante, face à complexidade do tema, as representações envolvendo pensamentos teleológicos e de razão necessária demandam outros estudos, focalizados nesta questão.

O Contraponto às Vivências da Atuação, quinta Categoria Temática, evidencia a busca dos profissionais por estabelecer elementos alternativos ao enfrentamento ou por uma nova compreensão da realidade que vivenciam e que não lhes parece definitiva. Os conteúdos sobre Contraponto se desdobraram em cinco Subcategorias: Histórias de Vida, Sofrimento, O Dia da Cura, Controle Emocional e Racionalidade Clínica.

Observa-se, em alguns casos, um estranhamento frente à forma de viver do paciente que, muitas vezes, revela-se completamente diferente das formas de viver a que profissional está habituado, fazendo com que este reflita sobre sua própria vida. Tal reflexão parece, com frequência, derivar das representações sobre o sofrimento humano e das formas com que este se manifesta, sobretudo na contraposição do sofrimento do profissional com o do paciente. Tal reflexão pode levar à subestimação do próprio sofrimento, mediante uma valorização do sofrimento da pessoa atendida: "A história de vida deles é interessante. Eles contam coisas que eu digo que a gente vive numa bola de cristal, usam termos, falam coisas... Um mundo diferente do que a gente conhece... Eles têm uma outra visão...” (Profissional 7); “Às vezes, estou chateada, vejo aquele paciente, com um problema mais sério... Então eu comparo o dele com o meu e acabo esquecendo o meu e vejo que o meu é muito pequeno perto do dele, me dá conforto, tenho mais vontade de viver, de lutar" (Profissional 3).

A expectativa da cura da Aids também se faz presente na atuação e demonstra o que o profissional espera de seu trabalho: "Eu sonho, um dia ver a cura... o que eu espero é um dia ver a cura... eu trabalho para tentar manter que as pessoas vivam, até que chegue a cura" (Profissional 1).

Partindo da perspectiva da pessoa contaminada, Souza (1994, p. 46) identifica o caráter paralisante das idéias de 
morte e seus desdobramentos para o sentido de continuidade que a perspectiva da cura encerra:

De repente, dei-me conta de que tudo havia mudado porque havia cura. De que a ideia de morte inevitável paralisa. Que a ideia de vida mobiliza... mesmo que a morte seja inevitável, como sabemos. Acordar, sabendo que se vai viver, faz tudo ter sentido de vida. Acordar pensando que se vai morrer, faz tudo perder o sentido. A ideia de morte é a própria morte instalada.

Assim, a expectativa da cura da Aids não serve somente como um elemento motivador, relacionado à vida da pessoa contaminada, mas também como um ponto de convergência, para o profissional de saúde, ligado à manutenção do trabalho, enquanto elemento que vitaliza a relação terapêutica. Segundo Ribeiro e cols. (2004) a crença sobre a necessidade de um constante acompanhamento, por parte dos profissionais que atuam em HIV/Aids, decorre da esperança que têm a respeito da cura da doença.

A necessidade de controlar as emoções durante a atuação se configura, também, como um contraponto aos elementos vivenciados na atuação: "O trabalho exige controle emocional, não chegar nervosa com o paciente, que já está nervoso. Não é minha vontade, é porque minha postura profissional exige..." (Profissional 6).

Para os profissionais entrevistados, embora a atuação suscite uma série de sentimentos, estes nem sempre podem ser demonstrados, já que podem ser incompatíveis com a postura profissional considerada adequada. E, dependendo da forma como profissional lida com esta situação, pode, a longo prazo, se tornar prejudicial à sua saúde mental.

A Racionalidade Clínica também aparece como contraponto a elementos psicossociais vivenciados na atuação. Para alguns dos profissionais entrevistados, um atendimento voltado exclusivamente para os elementos de competência técnica, na maioria das vezes, não se reverte em um atendimento de qualidade:

Eu achava que qualidade era o que eu fazia, atendia, examinava... prescrevia... via se tava o CD4 bom, carga viral indetectável e tava muito bem. Hoje eu tenho ouvido mais, sinto que eu melhorei, agora eu atendo o paciente mais como um todo (Profissional 7).

Pode-se observar, pelo depoimento, que tal percepção só foi possível no decorrer da atuação, ao longo do tempo, enquanto produto da apropriação do trabalho, pelo profissional. Segundo Monteiro (2006) tal percepção, originada na práxis profissional, representa um contraponto interessante ao conhecimento acadêmico, gerado nos cursos de graduação.

Finalmente, a Apropriação do Trabalho, ligada à autodeterminação e reconstrução do conhecimento, envolve processos de Auto-realização no Trabalho e Aprendizagem Informal. Participar dos processos de mudanças estruturais no trabalho possibilita ao profissional visualizar uma parte de si no cuidado exercido. Poder expressar a subjetividade no trabalho é uma conquista para além do cumprimento e reprodução de normas e protocolos em direção da autorrealização e da gratificação de poder ajudar o outro: "Tem um monte de coisa minha aqui, pedacinho por pedacinho... Aí você tem a certeza que está no lugar certo, onde queria estar... nesse ponto eu sou realizado..." (Profissional 1); “Tem sempre essa expectativa de ajudar o outro, uma recompensa pessoal..." (Profissional 2); "Faço o meu ambulatório funcionar para os pacientes, para que eles possam ter o que há de melhor..." (Profissional 10); "Fazer por fazer, eu não consigo, se eu estiver sentindo que está bom... Esse é um dos motivos que esse trabalho aqui é legal pra mim, porque eu consigo fazer... Sentir alegria... tristeza... o que for..." (Profissional 9).

Mediante os relatos obtidos neste estudo, observou-se que a apropriação do trabalho vem possibilitar uma visão clara da dialética da realização profissional, com base no processo de aquisição e sistematização da aprendizagem informal dentro do contexto do trabalho.

O trabalhador de saúde, ao se deparar com os limites do conhecimento técnico, busca, dentro do seu repertório de experiências, acumuladas ao longo do exercício das atividades de atendimento, elementos para criação de meios mais adequados para fazer frente às exigências que fogem à competência do saber especializado: "A gente sabe coisas um do outro (paciente e profissional) que, na minha opinião... Pra esse tipo de cuidado, de atenção faz muita diferença..." (Profissional 9).

No aprendizado técnico eu vou no livro... Alguma solução já tá escrita... Sobre as emoções você tem que aprender, não têm em nenhum lugar escrito; mais que o Freud, estudou, coitado... Mas não tem nada escrito... Você tem que procurar aprender, $e$ dentro daquilo, fazer o melhor que você puder $e$ isso acaba sendo muito mais do que a técnica, você acaba tendo que aprender muito mais, você aprende com o sofrimento, que é melhor você fazer daquele jeito... Nesse sentido eu aprendo muito... (Profissonal 6)

Observa-se, nesses depoimentos, que a relação estabelecida com a pessoa atendida pode ensejar outras formas de enfrentar suas demandas psicossociais. Figueiredo (2003) afirma que a sistematização do conhecimento informal, gerado no processo do trabalho, pode formar um background para o desenvolvimento de uma maior autonomia nos profissionais, tornando-os sujeitos ativos no atendimento a pessoas com HIV/Aids.

Campos (2000), discorrendo sobre o trabalho em saúde, afirma que este é organizado nos moldes tayloristas e regido por teorias fundamentadas no empirismo, prevalentes dentro 
da prática profissional, onde a criatividade e a autonomia são retiradas da prática profissional.

Esse saber ontologizado (não dialético, portanto), além da função político-institucional de concentrar o poder, provoca um duplo efeito: o de orientar e ajudar o sujeito a agir com segurança; mas também o de o cegar para as variações situacionais, dificultando, a experimentação e a invenção. (p. 172)

E, embora reconheça que tais teorias sejam fundamentais para a prática profissional, o autor ressalta que estas não deveriam se sobrepor ao conhecimento adquirido na atuação:

Se a subordinação do sujeito à teoria cristalizada implica alienação... caminhar sem referência às Teorias ou aos valores antes construídos significa a barbárie (...). O desafio estaria, novamente, em descobrir mediações que nos permitissem lidar com este dilaceramento sem a opção de optar por um de seus polos. (Campos, 2000, p. 172)

Assim, a sistematização da aprendizagem informal, enquanto conhecimento, pode favorecer o processo de apropriação do trabalho pelos profissionais da saúde, um trabalho no qual fazem parte do processo. Os profissionais de saúde que atuam em HIV/Aids deveriam ser capacitados para sistematizar e aproveitar a aprendizagem informal, acumulada durante o processo de atendimento ao paciente.

\section{Considerações finais}

A racionalidade técnica, ao eliminar os elementos subjetivos do processo de trabalho, incide na qualidade do atendimento em saúde, desvitalizando a relação profissionalusuário. Paradoxalmente, mesmo trabalhando sob o crivo da especialidade do saber, os participantes reconheceram que, neste contexto, a expressão da subjetividade é uma conquista em direção à autorrealização profissional. $\mathrm{O}$ contato com os usuários do atendimento e suas demandas psicossociais remetem os profissionais às questões necessárias à formação de vínculo e à revitalização da relação terapêutica. Neste estudo, um sentimento de impotência e inaptidão para lidar com estas questões, levaram o profissional a, muitas vezes, relegá-las a um plano secundário. A complexidade do trabalho com HIV/Aids requer, dos profissionais da saúde, uma atuação integrada, considerando seus elementos técnicos e psicossociais. Sua sensibilidade frente ao paciente e às vicissitudes do convívio com a Aids é uma das condições fundamentais que podem determinar a diferença entre o êxito e o fracasso na manutenção da vitalidade e da esperança. Independente da categoria e da qualificação técnica do profissional, a atuação deve ser pautada na simetria da relação entre pessoas, valorizando e reconhecendo a experiência adquirida, na prática, pelos profissionais.

\section{Referências}

Alves, E. G. R., \& Ramos, D. L. P. (2002). Profissionais de saúde: Vivendo e convivendo com HIV/Aids. São Paulo: Santos.

Ayres, J. R. C. M. (2004). Cuidado e reconstrução das práticas de saúde. Interface: Comunicação, Saúde, Educação, 8, 73-92.

Barroso, L. M. M., \& Galvão, M. T. G. (2007). Avaliação do atendimento prestado por profissionais de saúde a puérperas com HIV/Aids. Texto \& Contexto Enfermagem, 16, 463-469.

Camargo Junior, K. R. (1992). (Ir)racionalidade médica: Os paradoxos da clínica. Physis: Revista de Saúde Coletiva, 2(1), 203-228.

Camargo Junior, K. R. (1994). A Aids e a Aids das ciências: $O$ discurso médico e a construção da Aids (pp. 43-48). Rio de Janeiro: Relume-Dumará.

Camargo Junior, K. R. (2003). Prevenções de HIV/Aids: Desafios múltiplos. Divulgação em Saúde para Debate, 27, 70-80.

Camargo Junior, K. R. (2005). A biomedicina [Versão eletrônica]. Physis: Revista de Saúde Coletiva, 15, 177-201. Recuperado em 07 outubro 2008, de http://www.scielo. br/pdf/physis/v15s0/v15s0a09.pdf

Campos, G. W. S. (2000). Um método para a análise e cogestão de coletivos. A constituição do sujeito, a produção de valor de uso e a democracia em instituições: O método da roda. São Paulo: Hucitec.

Cardoso, G. P., \& Arruda, A. (2004). As representações sociais da soropositividade e sua relação com a observância terapêutica. Ciência \& Saúde Coletiva, 10, 151-162.

Figueiredo, M. A. C. (1994). Profissionais de saúde e atitudes frente à Aids: Um estudo diferencial com base no modelo afetivo-cognitivo de Fishbein e Ajzen. Tese de livre docência não-publicada, Universidade de São Paulo, Ribeirão Preto, SP.

Figueiredo, R. M. (1994). A enfermagem diante do paciente com Aids e a morte. Dissertação de mestrado não-publicada, Universidade de Campinas, Campinas, SP.

Figueiredo, M. A. C. (1998). Escalas afetivo cognitivas de atitude: Construção validação e interpretação de resultados. In G. Romanelli \& Z. M. M. Biasoli-Alves (Orgs.), Diálogos metodológicos sobre a prática de pesquisa (pp. 51-70). Ribeirão Preto, SP: Legis Summa.

Figueiredo, M. A. C. (2000). Aids, ciência e sociedade: A dicotomia entre conhecimento técnico e competência social no trabalho do profissional de saúde. In M. L. Boarini (Org.), Desafios na atenção à saúde mental (pp. 79-92). Maringá, PR: EdUEM.

Figueiredo, M. A. C. (2003). Avaliação de um programa de orientação e suporte psicossocial ao cuidado doméstico de pessoas que vivem com HIV/Aids: Um estudo com base na tríade paciente/profissional/familiar. Manuscrito não-publicado, Universidade de São Paulo, Ribeirão Preto, SP. 
Herrera, C., Campero, L., Caballero, M., \& Kendall, T. (2008). Relación entre médicos y pacientes con VIH: Influencia en apego terapéutico y calidad de vida. Revista de Saúde Pública, 42, 249-255.

Minayo, M. C. (2003). Hermenêutica-dialética como caminho do pensamento social. In M. C. Minayo \& S. F. Deslandes (Orgs.), Caminhos do pensamento: Epistemologia e método (pp. 83-107). Rio de Janeiro: Fiocruz.

Minayo, M. C. (2004). O desafio do conhecimento: Pesquisa qualitativa em saúde (8a ed.). São Paulo: Hucitec.

Monteiro, J. F. A. (2006). O processo de trabalho em HIV/ Aids: A visão dos profissionais. Dissertação de mestrado não-publicada, Universidade de São Paulo, Ribeirão Preto, SP.

Nogueira-Martins, L. A. (2003). Saúde mental dos profissionais da saúde. Revista Brasileira de Medicina do Trabalho, 1, 56-68.

Oliveira, L. A., \& França Junior, I. (2003). Demandas reprodutivas e a assistência às pessoas vivendo com HIV/ Aids: Limites e possibilidades no contexto dos serviços de saúde especializados. Cadernos de Saúde Pública, 19, 315-323.

Oltamari, L. (2004). As políticas da Aids em um mundo globalizado: Uma relação entre doença e política da ciência. Revista Brasileira de Ciências Sociais, 19(54), 175-178.

Quintana, A. M., Kegler, P., Santos, M. S., \& Lima, L. D. (2006). Sentimentos e percepções da equipe de saúde frente ao paciente terminal. Paideia (Ribeirão Preto), 16, 415-425.

Resuto, T. J. O., Mendes, S. N., Oliveira, M. T., \& Lourenço, E. L. (2000). A assistência de enfermagem aos portadores de HIV/Aids no vislumbrar da sua epidemia em Ribeirão Preto: Relato de experiência de uma equipe de enfermagem. Revista da Escola de Enfermagem USP, 34, 240-243.

Ribeiro, C. G., Coutinho, M. P. L., \& Saldanha, A. A. W. (2004). Estudo das representações sociais sobre a Aids por profissionais de saúde que atuam no contexto da soropositividade para o HIV. DST: Jornal Brasileiro de Doenças Sexualmente Transmissíveis, 16(4), 14-18.

Rissi, M. R. R. (2001). Profissionais da saúde e Aids: Um estudo diferencial frente a ocorrência de acidentes ocupacionais com material biológico potencialmente contaminado. Dissertação de mestrado não-publicada, Universidade de São Paulo, Ribeirão Preto, SP.

Sadala, M. L. A., \& Marques, S. A. (2006). Twenty years of care for persons living with HIV/Aids in Brazil: The health professionals' perspective. Cadernos de Saúde Pública, 22, 2369-2378.

Silva, N. E. K., Oliveira, L. A., Figueiredo, W. S., Landroni, M. A. S., Waldman, C. C. S., \& Ayres, J. R. C. M. (2002). Limites do trabalho multiprofissional: Estudo de caso dos centros de referência para DST/Aids. Revista de Saúde Pública, 36, 108-116.
Soares, J. C. R. S., \& Camargo Junior, K. R. (2007). A autonomia do paciente no processo terapêutico como valor para a saúde [Versão eletrônica]. Interface: Comunicação, Saúde, Educação, 11, 65-78. Recuperado em 08 outubro 2008, de http://www.scielo.br/scielo. php?script $=$ sci_arttext\&pid=S1414-3283200700010000 $7 \& \operatorname{lng}=$ en\&lng=en\&nrm=iso

Souza, H. (1994). A cura da Aids. Rio de Janeiro: RelumeDumará.

Terto Junior, V. S. (1996). Homossexuais soropositivos e soropositivos homossexuais: Questões da homossexualidade masculina em tempos de Aids. In R. Parker \& R. M. Barbosa (Orgs.), Sexualidades brasileiras (pp. 90-104). Rio de Janeiro: Relume-Dumará.

Joana Filipa Afonso Monteiro é doutoranda do Programa de Pós-graduação em Psicologia da Faculdade de Filosofia, Ciências e Letras de Ribeirão Preto da Universidade de São Paulo.

Marco Antonio de Castro Figueiredo é Professor Titular do Departamento de Psicologia e Educação da Faculdade de Filosofia, Ciências e Letras de Ribeirão Preto da Universidade de São Paulo.
Recebido: 22/04/2008

$1^{a}$ revisão: $10 / 11 / 2008$

Aceite final: 11/02/2009 